\title{
Effects of soil moisture and treatment volume on bentazon mobility in soil
}

\author{
Sophie GuimonT*, Corinne Perrin-Ganier, Benoît Real, Michel Schiavon \\ Laboratoire Sols et Environment, UMR 1120, INPL/ENSAIA-INRA, 2 avenue de la Forêt de Haye, BP 172, 54505 Vandœuvre-lès-Nancy, France
}

(Accepted 11 January 2005)

\begin{abstract}
Soil moisture affects the leaching behaviour of pesticides by inducing their physical entrapment in the soil structure. Columns containing soil aggregates were dampened to specific initial moisture levels. Bentazon was dripped onto surface aggregates in different volumes. The columns were then percolated after an equilibration period. Soil water from the columns was divided arbitrarily among mobile and immobile regions in order to describe the herbicide redistribution processes in the soil. When the soil was dry before treatment, bentazon losses by mass flow were 1.5 to 4 times higher than in wet conditions. Between application time and percolation, any water present in the porous matrix might favour pesticide diffusion towards immobile water regions as well as adsorption into and onto soil aggregates, preventing its leaching. The use of large solution volumes of the pesticide modifies surface soil moisture, suppressing any difference in behaviour between dry and wet soil application conditions.
\end{abstract}

bentazon / diffusion / leaching / mobile water / immobile water

\section{INTRODUCTION}

Summer pesticide application might be done in dry or wet soil conditions. According to the soil's moisture state, pesticide spread over a given land surface might either crystallise on contact with dry soil or dissolve on wet soil. After periods of low or no rainfall, the pesticide would not be able to evolve or to move in the soil surface layer, whereas in wet conditions, the pesticide could interact with soil particles. Thus, the weather conditions preceding pesticide application may considerably affect the behaviour of the product in the soil.

Several authors have studied soil moisture effect at the time of treatment on solute movement in soil. Rao et al. (1974) mentioned, in field experiments, later and lesser picloram leaching when applied on air-dry soil (evaporation) compared with wet soil. The opposite was observed when studying mobile herbicides' (isoproturon and mecocrop) transfer through a loamy clay soil (Brown et al., 1995a). In a soil column experiment, Shipitalo et al. (1990) pointed out the effect on solute (bromide, strontium and atrazine) availability to transfer of slight precipitation occurring prior to heavy rainfall. Laboratory studies have also displayed the variability of pesticide movement depending on the humidity level of the soil (Geissbuhler et al., 1963; Green et al., 1968). A recent work (Beulke et al., 2004) concluded that variations in moisture level had no effect on isoproturon leaching and availability in soil water. These studies were all based on soil columns that had been dampened to a greater or lesser extent at the time of applying the pesticide and brought to field capacity before leaching.

Water resource management requires an understanding of the mechanisms and original conditions responsible for pesticide pollution. In order to comprehend solute movement in soils, Van Genuchten and Wierenga (1976) conceptualised soil as a porous medium composed of two distinct but connected continuums. Liquid pore volume is divided into two regions: a region of mobile water occupying the coarse pores of soil (macropores); and an immobile region, referring to intra-aggregate porous space (meso-, micro- and nanopores). Solutes move by convective flow through the mobile region (White et al., 1986; Hagerman et al., 1989; Brown et al., 1995b), whereas intraaggregate space is accessible mainly by molecular diffusion (Nye, 1979; Koch and Flühler, 1993) but also by convection (Jury and Flühler, 1992). The extent and redistribution of pesticides by water are controlled both by soil and compound characteristics and by environmental conditions, among which climatic conditions predominate (Yaron et al., 1996).

This work aims to determine the effects of soil initial moisture and the mode of pesticide application on product redistribution in mobile and immobile regions. Small columns filled with soil aggregates were saturated with water to distinct moisture levels and treated with bentazon. We varied the formulation and

\footnotetext{
* Corresponding author: Sophie.Guimont@ensaia.inpl-nancy.fr
} 
Table I. Selected top soil properties of the six soils used in the study.

\begin{tabular}{|c|c|c|c|c|c|c|c|}
\hline \multirow{2}{*}{ Soil series } & \multirow{2}{*}{ Classification ${ }^{1}$} & \multicolumn{3}{|c|}{ Textural class $(\%)$} & \multirow{2}{*}{$\mathrm{pH}_{\text {water }}$} & \multirow{2}{*}{$\begin{array}{c}\text { Organic Matter } \\
(\%)\end{array}$} & \multirow{2}{*}{$\mathrm{RC}^{2}$} \\
\hline & & Clay & Silt & Sand & & & \\
\hline Bouzule clay & vertic stagnic cambisol & 41.1 & 48.6 & 10.3 & 6.9 & 3.32 & 36.7 \\
\hline Villey clay & stagnic cambisol & 53.6 & 39.7 & 6.7 & 6.7 & 5.81 & 50.7 \\
\hline Bouzule loam & stagnic luvisol & 30.9 & 50 & 19.1 & 5.9 & 2.62 & 32.1 \\
\hline Kerlavic loam sand & dystic cambisol & 17.7 & 45.2 & 37.1 & 5.3 & 6.03 & 35.4 \\
\hline Villey sand & fluvic stagnic cambisol & 11.4 & 22.5 & 66.1 & 5.8 & 1.5 & 19.1 \\
\hline Corcieux sand & eutric cambisol & 10.4 & 19 & 70.6 & 6.2 & 3.66 & 17.9 \\
\hline
\end{tabular}

${ }_{1}^{1}$ World Reference Base classification (1998).

2 Retention Capacity determined by pressure technique.

application volumes of the bentazon solution. Bentazon is a herbicide, used for cereal protection, chosen in this study as a model because of its high solubility in water (Abernathy and Wax, 1973; Huber and Otto, 1994) and its weak adsorption on soil constituents (Grey et al., 1996; Boivin et al., 2004). By successive stages of percolation and centrifugations, we analysed the amounts of bentazon transferred by mass flow and the concentration spread in the immobile water compartments. The experiment was carried out in six soils with contrasting physico-chemical properties.

\section{MATERIALS AND METHODS}

\subsection{Soil columns}

For this study, five agricultural soils were selected in the Lorraine region of Northeastern France and one in Brittany (Western France), each representing a major textural class (clay, loam or sand) and a high or low organic matter level (Tab. I). Soil retention capacity (RC) was determined for each soil (Tab. I) by the pressure method, whereby RC corresponds to the maximal amount of capillary water retained by a soil (Duchauffour, 1970).

After being air-dried, soil samples (surface layer 5-15 cm) were sieved between 2 and $5 \mathrm{~mm}$ so that their structure ressembled that of an aggregated seedbed. Small soil columns were made by filling Whatman Autovials ${ }^{\circledR}$ (diameter $2 \mathrm{~cm} \times 6.5 \mathrm{~cm}$ height, Fig. 1) with dry soil aggregates. Aggregate columns were either left to dry or dampened to $50 \%$ or $100 \%$ of soil retention capacity. When the pesticide was applied in a large volume of solution (cf. Sect. 2.2.2), the theoretical water volume required to dampen the soil to $100 \%$ of RC was adapted.

\subsection{Pesticide}

\subsubsection{Pesticide characteristics}

Bentazon (3-isopropyl-1H-2,1,3-benzothiadiazine-4(3H)one-2,2-dioxide) is a weak acid (pKa 3.3) selected for its high water solubility $\left(570 \mathrm{mg} \cdot \mathrm{L}^{-1}\right.$ at $\left.\mathrm{pH} 7,22{ }^{\circ} \mathrm{C}\right)$ and its weak adsorption on soil (mean Kd value $0.6 \mathrm{~cm}^{3} \cdot \mathrm{g}^{-1}$ ) (Huber and Otto, 1994). Specific bentazon adsorptions by the 6 soils studied were previously measured using standard equilibration techniques (Boivin, 2003). Their Kd values are reported in Table II.

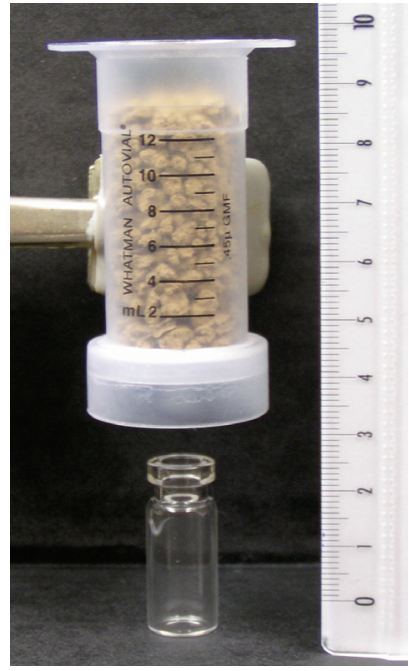

Figure 1. Experimental column (Whatman Autovial®) filled with dry soil aggregates: an autosampler vial can be attached to the tip.

Table II. Bentazon adsorption characteristics by the 6 soils studied (Boivin, 2003).

\begin{tabular}{ll}
\hline Soil series & Kd \\
\hline Bouzule clay & 1.2 \\
Villey clay & 1.4 \\
Bouzule loam & 1.4 \\
Kerlavic loam sand & 1.9 \\
Villey sand & 1.4 \\
Corcieux sand & 1.3 \\
\hline
\end{tabular}

\subsubsection{Pesticide application}

The wet columns were left to equilibrate for a $16 \mathrm{~h}$ period and then [phenyl-U- ${ }^{14} \mathrm{C}$ ] bentazon (radiochemical purity $>99 \%$; specific activity $6.69 \mathrm{MBq} \cdot \mathrm{mg}^{-1}$; BASF, Germany) was added $(0.3-0.4 \mu \mathrm{g}$ according to the daughter solution preparation) to each soil column. In a first experiment concerning the six soils, bentazon was applied to the top aggregates in $0.02 \mathrm{~mL}$ 
(small volume) dichloromethane solution (bentazon solubility $\left.206 \mathrm{~g} \cdot \mathrm{L}^{-1}\right)$. Dichloromethane solvent was used for its high volatility in order to initiate rapid bentazon precipitation on the soil aggregates' surface. The applied volume when compared with the column area is equivalent to a field treatment volume of $526 \mathrm{~L} \cdot \mathrm{ha}^{-1}$ commonly practised by farmers in the past. Using a microsyringe, the solution was distributed in microdroplets all over the surface aggregates in order to mimic field spraying. In a second experiment, bentazon dissolved in $1 \mathrm{~mL}$ (large volume) aqueous solution (bentazon solubility $570 \mathrm{mg} \cdot \mathrm{L}^{-1}$ ) was applied to top aggregates using a pipette. This latter volume, 50 times higher than the precedent application volume, is closer to the common treatment volume applied in laboratory studies. The application of a larger volume of pesticide solution required decreasing by $1 \mathrm{~mL}$ the water volumes necessary to dampen soil columns before treatment. For this second experiment, we focused on three soils (Bouzule clay, Bouzule loam and Corcieux sand) representing major textural classes, and two soil water content levels (dry or $100 \%$ of RC).

Each soil column represented a single type of soil, a given humidity level and a given volume of bentazon solution (4 replicates per treatment).

\subsection{Experimental method}

\subsubsection{Leaching study}

The treated columns were sealed with parafilm and stored for 6 days at room temperature $\left(20 \pm 2{ }^{\circ} \mathrm{C}\right)$. No water was added during this period. Subsequently, all the columns were eluted with distilled water using a peristaltic multi-channel pump (Ismatec model mp25) at an arbitrary flow rate of $1 \mathrm{~mm} \cdot \mathrm{min}^{-1}$, fixed with the intention of facilitating the exchanges between mobile and immobile waters as well as processes of solubilisation and adsorption/desorption. We aimed to add a total of $16.5 \mathrm{~mL}$ - equivalent to an intense rainfall in spring or summer - to each column, when both the soil-dampening stage (concerning exclusively wet columns) and percolation stage were taken together. The dry columns were percolated with $16.5 \mathrm{~mL}$. The columns initially dampened to $50 \%$ or $100 \%$ of RC were percolated with a volume equivalent to the difference between $16.5 \mathrm{~mL}$ and the volume of water already applied during the soil-dampening stage.

All the mobile water was collected and weighed at the end of the percolation. ${ }^{14} \mathrm{C}$-bentazon concentration was measured immediately after percolation by liquid scintillation (Packard Tri-Car 460 CD): $1 \mathrm{~mL}$ was counted in $10 \mathrm{~mL}$ Ultima Gold Scintillator-Packard. This aimed both at characterising the fraction of soil water and bentazon available by convective transport, through inter-aggregate space, during leaching events, and at quantifying bentazon transfer.

\subsubsection{Immobile water content characterisation}

The columns (Whatman ${ }^{\circledR}$ autovial) consisted of a barrel with a perforated base covered by a glass microfibre filter allowing a sampler vial to be attached (Fig. 1). After percolation, the columns were centrifuged (Beckman Avanti Centrifuge J25) successively at $333 g$ (5 $\mathrm{min})$ and $7244 \mathrm{~g}$ (7 $\mathrm{min})$. Previous experiments had shown that longer times of centrif- ugation did not allow any further water to be collected and were destructive for the experimental device. Each corresponding water fraction was collected in a sampler vial attached to the base tip of the column. Both fraction volumes were determined by weighing and the ${ }^{14} \mathrm{C}$-bentazon concentration was determined by liquid scintillation counting. The purpose of this was to estimate the water storage capacity of two different immobile water compartments and to characterise the bentazon concentration therein. Data (volume and herbicide content) concerning the residual water fraction (a third immobile region) remaining after centrifugations were inferred from weighing and calculation. In order to check bentazon residual amounts in the soil by measurement, combustion of air-dried and pulverised soil samples was performed in parallel after centrifugations, for several columns of each treatment. No significant differences appeared between calculated and measured data.

\subsection{Statistical analysis}

The effects of initial soil aggregate moisture and the application volume on bentazon amounts transferred into mobile water and the bentazon levels in immobile regions were tested through a variance analysis (ANOVA).

\section{RESULTS AND DISCUSSION}

\subsection{Water compartments of aggregate columns}

The total soil solution volumes recovered after the percolation and centrifugation stages are presented in Table III. No significant difference in volume was noted between dry and wet ( 50 or $100 \%$ of RC) columns. The proportion of the volume of the different water regions (percolated water, $333 \mathrm{~g}$ extracted water and $7244 \mathrm{~g}$ extracted water) in relation to the total water collected is also reported in Table III.

\subsection{Bentazon mass flow transfer behaviour}

\subsubsection{Small volume application}

Table IV presents the amounts of bentazon transferred by mass flow in mobile water, for the six soils studied, according to initial soil moisture (dry, dampened to $50 \%$ of RC, or dampened to $100 \%$ of RC).

When bentazon was applied to dry soil aggregates, bentazon amounts in mobile water accounted for $42.1 \%$ (Bouzule loamy soil) to $58.1 \%$ (Villey clay soil) of the initial dose. No statistical differences between soils were revealed by variance analysis (Tab. IV). Conversely, bentazon application on wet soil led to a significant decrease in amounts exported by macroporal flow for each soil: 1.5 to 4 times less herbicide was measured in percolates, with the unexplained exception of Villey sandy soil. Moreover, bentazon mass transfer remained unaltered by aggregate water saturation level (50 or $100 \%$ of RC).

\subsubsection{Large volume application}

Bentazon exportations by mass flow, according to soil initial moisture (dry or $100 \%$ of $\mathrm{RC}$ ) when a 50 times greater $(1 \mathrm{~mL})$ 
Table III. Total soil solution recovered after leaching and centrifugations of dry soil columns (low volume of treatment) and proportion of the different water compartments (means of 4 replicates).

\begin{tabular}{|c|c|c|c|c|c|c|c|c|c|}
\hline Soil series & $\begin{array}{c}\text { Total soil } \\
\text { solution }(\mathrm{mL})\end{array}$ & $\begin{array}{l}\text { Leachate } \\
\text { (\% of total) }\end{array}$ & SD & $\begin{array}{c}333 \text { g water } \\
\text { extracted } \\
(\% \text { of total })\end{array}$ & SD & $\begin{array}{c}7244 \text { g water } \\
\text { extracted } \\
(\% \text { of total })\end{array}$ & SD & $\begin{array}{c}\text { Residual } \\
\text { water } \\
\text { (\% of total) }\end{array}$ & SD \\
\hline Bouzule clay & 15.8 & 63.9 & 0.5 & 5.7 & 0.7 & 7.2 & 0.4 & 23.2 & 0.5 \\
\hline Villey clay & 16.6 & 68.3 & 1.7 & 5.9 & 0.3 & 6.7 & 0.2 & 18.0 & 0.2 \\
\hline Bouzule loam & 16.4 & 71.1 & 0.7 & 4.4 & 0.4 & 6.4 & 0.3 & 18.0 & 0.1 \\
\hline Kerlavic loam sand & 16.0 & 75.6 & 2.4 & 3.5 & 0.6 & 8.1 & 0.4 & 12.8 & 0.7 \\
\hline Villey sand & 16.3 & 82.6 & 1.5 & 3.2 & 0.2 & 5.6 & 0.4 & 8.5 & 0.3 \\
\hline Corcieux sand & 16.2 & 76.5 & 10.0 & 1.8 & 1.0 & 7.6 & 0.4 & 14.1 & 0.5 \\
\hline
\end{tabular}

Standard Deviation (SD) indicates error between the replicates.

Table IV. Small volume of treatment: mean mobile water bentazon amounts per column after 6 days of equilibration.

\begin{tabular}{|c|c|c|c|c|c|c|}
\hline & \multicolumn{2}{|c|}{ dry } & \multicolumn{2}{|c|}{$50 \%$ of $\mathrm{RC}$} & \multicolumn{2}{|c|}{$100 \%$ of RC } \\
\hline & $\begin{array}{l}\text { leached amounts } \\
\text { (\% of initial dose) }\end{array}$ & SD & $\begin{array}{l}\text { leached amounts } \\
\text { (\% of initial dose) }\end{array}$ & SD & $\begin{array}{l}\text { leached amounts } \\
\text { (\% of initial dose) }\end{array}$ & SD \\
\hline Bouzule clay & $45.7 \mathrm{a}$ & 0.7 & $33.4 \mathrm{~b}$ & 2.4 & $26.6 \mathrm{c}$ & 2.3 \\
\hline Villey clay & $58.1 \mathrm{a}$ & 14.3 & $22.5 b$ & 3.3 & $24.6 b$ & 1.7 \\
\hline Bouzule loam & $42.1 \mathrm{a}$ & 2.8 & $11.2 \mathrm{~b}$ & 2.7 & $9.7 \mathrm{~b}$ & 6.4 \\
\hline Kerlavic loam sand & $49.9 \mathrm{a}$ & 10.0 & $30.4 \mathrm{~b}$ & 8.8 & $32.1 \mathrm{~b}$ & 5.1 \\
\hline Villey sand & $53.9 \mathrm{a}$ & 5.5 & $48.8 \mathrm{a}$ & 4.4 & $53.6 \mathrm{a}$ & 0.8 \\
\hline Corcieux sand & $52.3 \mathrm{a}$ & 6.5 & $22.0 \mathrm{~b}$ & 4.0 & $17.3 b$ & 5.1 \\
\hline
\end{tabular}

Letters $\mathrm{a}, \mathrm{b}$ and $\mathrm{c}$ refer to variance analysis of initial moisture effect on bentazon exportations by soil (the same letters indicate no significant differences between treatments). Standard Deviation (SD) indicates error between the replicates.

Table V. Large volume of treatment: mean mobile water bentazon amounts per column after 6 days of equilibration.

\begin{tabular}{lcccc}
\hline & \multicolumn{2}{c}{ dry } & \multicolumn{2}{c}{$100 \%$ of RC } \\
\cline { 2 - 5 } & $\begin{array}{c}\text { leached } \\
\text { amounts } \\
\text { (\% of initial } \\
\text { dose })\end{array}$ & SD & $\begin{array}{c}\text { leached } \\
\text { amounts } \\
\text { \% of initial } \\
\text { dose })\end{array}$ & SD \\
\hline Bouzule clay & 29.5 & 4.0 & 26.1 & 1.5 \\
Bouzule loam & 17.8 & 2.0 & 17.9 & 1.2 \\
Corcieux sand & 20.5 & 2.1 & 20.7 & 1.5 \\
\hline
\end{tabular}

No statistical differences were revealed by the variance analysis of initial moisture effect on bentazon exportations by soil. Standard Deviation (SD) indicates error between the replicates.

volume is applied of an aqueous bentazon solution are presented in Table V. For the three soils, percolated bentazon amounts ranged from $17.8 \%$ to $29.5 \%$, when soil aggregates were dry previous to pesticide application, and from $17.9 \%$ to $26.1 \%$ when they were wet. It would seem that an increased treatment volume limited the initial soil moisture effect we observed previously. Indeed, for each of the three soils (Bouzule clay, Bouzule loam and Corcieux sand), the same herbicide amounts were recovered in mobile water, whatever the initial aggregate water saturation.

\subsection{Bentazon redistribution in immobile water compartments}

\subsubsection{Small volume application}

The bentazon distribution in the various water compartments of three soils selected from the panel (Bouzule clay, Bouzule loam and Corcieux sand), after percolation and centrifugations of treated columns by a weak volume on dry aggregates, is represented in Figure $2 \mathrm{a}$. The product is divided into the distinct soil water regions (mobile and immobile regions). Mean bentazon concentrations for the three soils in the three immobile water regions, meso-, microporal and residual, were, respectively, $18.2 \pm 2.5 \mu \mathrm{g} \cdot \mathrm{L}^{-1}, 23.2 \pm 6.8 \mu \mathrm{g} \cdot \mathrm{L}^{-1}$ and $42.4 \pm 10.2 \mu \mathrm{g} \cdot \mathrm{L}^{-1}$.

When treatment was carried out with a small volume on wet aggregates (Fig. 2b), the bentazon levels divided between the fine porosity compartments, for the same soils, were statistically lower than with initially dry aggregates: $7.3 \pm 3 \mu \mathrm{g} \cdot \mathrm{L}^{-1}$ and $10.5 \pm 5.8 \mu \mathrm{g} \cdot \mathrm{L}^{-1}$ in meso- and microporal waters. Because no effect of soil water saturation was revealed by variance analysis, only data relative to soil dampened to $100 \%$ of RC are presented in Figure 2b. It can be noticed that a majority of the herbicide remains in the residual water $\left(48.5 \pm 1.5 \mu \mathrm{g} \cdot \mathrm{L}^{-1}, 89.5 \pm\right.$ $7.7 \mu \mathrm{g} \cdot \mathrm{L}^{-1}$ and $98.6 \pm 7.6 \mu \mathrm{g} \cdot \mathrm{L}^{-1}$, respectively, for the Bouzule clay, the Bouzule loam and the Corcieux sandy soils). 

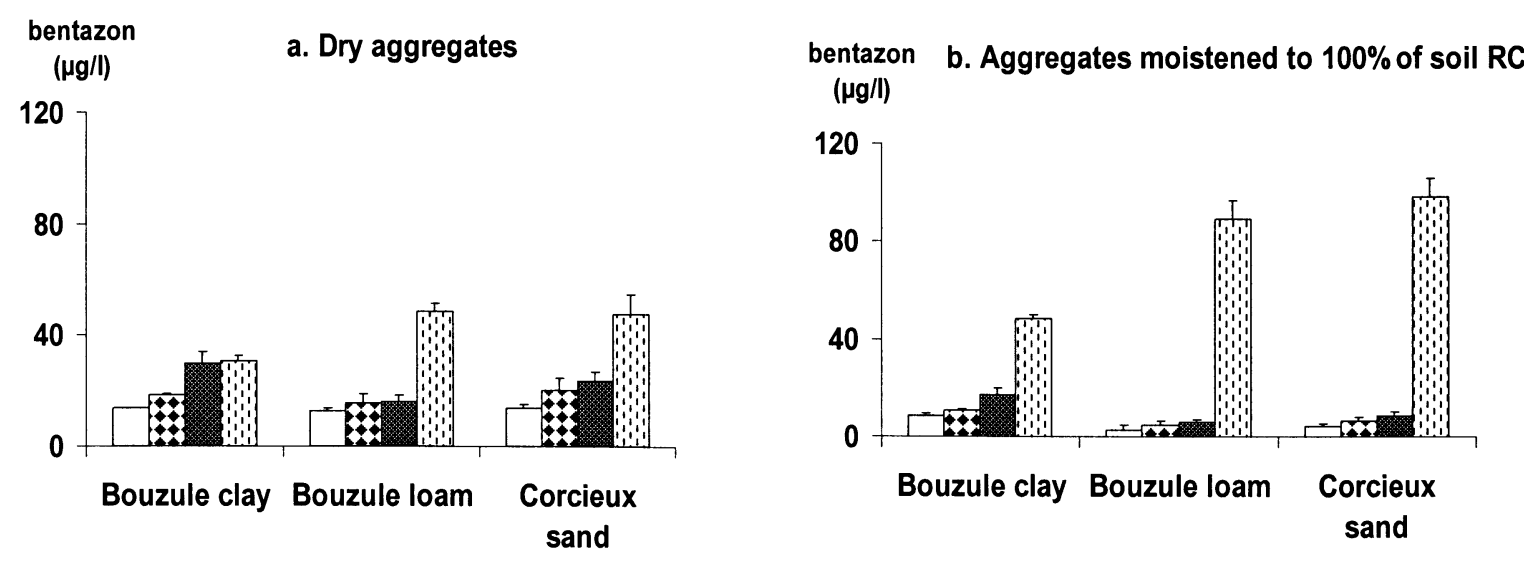

Figure 2. Small volume application: bentazon concentrations of mobile water $\square$; mesoporal water 楀; microporal water $\square$; residual water $\square$ of 3 soils from the panel.
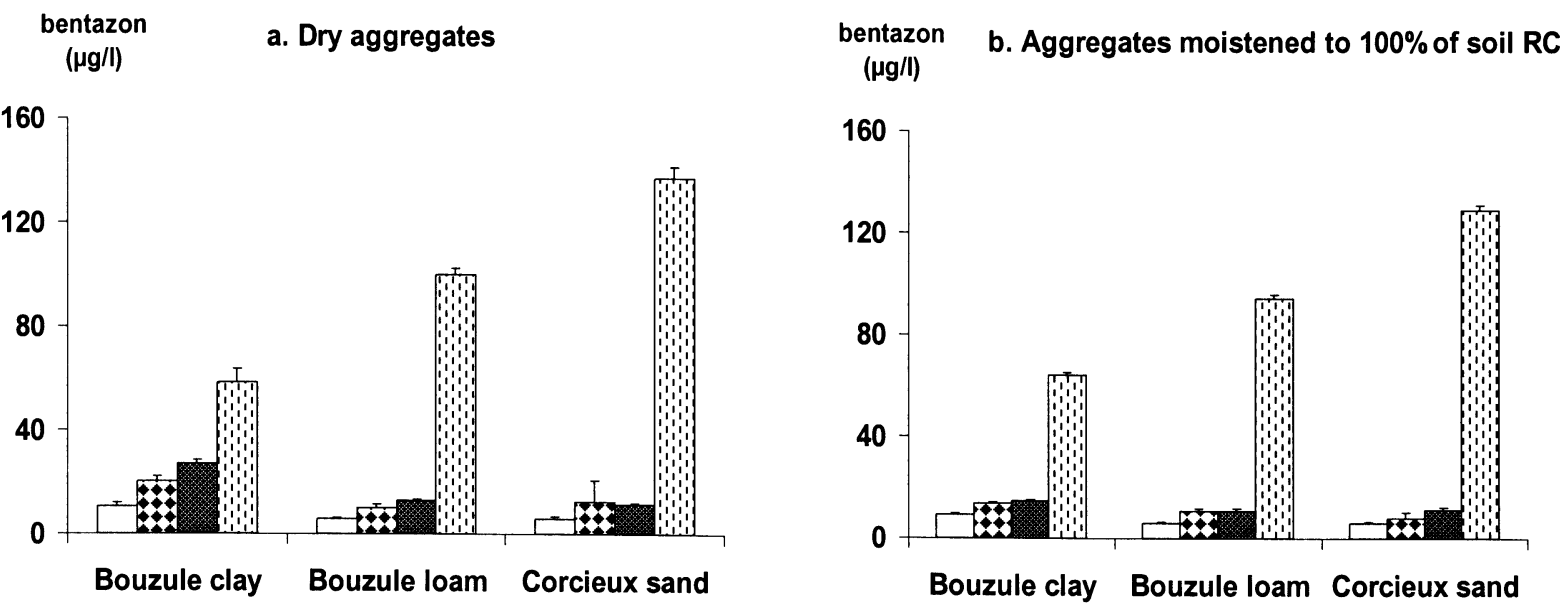

Figure 3. Large volume application: bentazon concentrations of mobile water $\square$; mesoporal water $\mathrm{D}$; microporal water $\square$; residual water $\square$ of 3 soils from the panel.

\subsubsection{Large volume application}

Adding bentazon in greater volumes $(1 \mathrm{~mL})$, as practised in laboratory studies based on the experimental model, tended to reduce the initial moisture effect previously observed between dry and wet soil. Redistribution profiles proved to be similar for Bouzule loam and Corcieux soils, whatever their initial humidity level (dry or wet), as shown in Figure 3. In the case of Bouzule clay soil, treatment in wet conditions promoted bentazon redistribution in residual water to the detriment of mesoand microporal waters.

\subsection{Significance}

The soil solution in columns of aggregates was divided arbitrarily into several regions. A first region constituted temporary water filling, in water-saturated soil conditions, of the spaces between aggregates (macroporosity). This mobile water obeys the laws of gravity. The water extracted by centrifugation at $333 \mathrm{~g}$ filled medium-size pores, whereas water extracted at $7244 \mathrm{~g}$ filled the finest soil pores. Because they are strongly retained, water from these two compartments is considered to be immobile. Water remaining in the column after centrifugations would correspond to immobile water located within soil nanopores and/or water adsorbed on soil constituents. A pesticide introduced into the system would be likely to be split up into the different types of water by convection and/or diffusion processes.

The results of the study show that bentazon redistribution within soil porosity may be significantly affected by the pesticide application mode and by the initial soil humidity level at the time of pesticide treatment. When dissolved in a weak dichloromethane volume and dripped on dry aggregates, bentazon is quickly crystallised on aggregate surfaces, because of 
the almost instantaneous volatilisation of the solvent. During the equilibration period, the immobilised product was unlikely to undergo either physical, chemical or biological phenomena because of the maintained dry state of the aggregates. The compound is then re-solubilised and transported through the porous network by water percolation. Capillary forces developed by micropores carry the water and bentazon away into fine porosity, even if the phenomenon is limited by the presence of air (Youngs et al., 1994). Bentazon is simultaneously transported by convection in macroporosity. Once inside the immobile water regions, exchanges of herbicide with mobile water are limited by water flow velocity: little time is left for diffusion to take place (Hartley, 1964). High concentrations may be diffused in capillary spaces. Bentazon in mobile water, during its spread in soil porosity, could be subject to a quick adsorption phenomenon (Boivin et al., 2004). Despite the short contact time, a part of the initial pesticide amount would be retained on external sorption sites of the soil particles. A direct transfer of pesticide in microcrystal form cannot be excluded. Amounts transferred by mass flow represent half of the applied dose. The "small volume application on dry soil" combination preserves a relative availability of the product to leaching and confers upon capillary pores the role of pesticide storage.

No influence of the initial water saturation degree (50 or $100 \%$ ) of the soil was revealed concerning the bentazon level in mobile and immobile regions in the case of a weak application volume $(20 \mu \mathrm{L})$. Bentazon transport can be discussed for the case of wet columns in comparison with dry columns. Due to its high solubility in water, the molecule is dissolved in water surrounding soil particles during solvent disappearance. During the equilibration time, between application and percolation, bentazon diffuses in the continuum of immobile water according to concentration gradients. The compound is thereby redistributed in different regions of fine porosity (Yaron et al., 1996). As a consequence, bentazon molecules finish by being physically trapped in immobile water regions. Concentrations measured in meso- and microporous regions might represent only a trace of the solute passing: the highest concentrations were observed in residual water (till $98.6 \mu \mathrm{g} \cdot \mathrm{L}^{-1}$ for Corcieux sandy soil). Nevertheless, it would seem that these latter concentrations also refer to bentazon adsorbed on accessible sites.

When percolation water arrives on a saturated or nearly saturated soil, no bentazon can be carried by capillary invasion. Mobile water takes a direct route through macroporous regions, carrying away part of the bentazon weakly adsorbed on coarse pore surfaces, without modifying the content of meso- and micropores filled with water (Gwo et al., 1995). Indeed, the time necessary to reverse the direction of bentazon diffusion from immobile regions towards mobile regions would be greater than the elution time of the experiment. Bentazon amounts exported by mass flow are thus considerably lower than after treatment on dry soil. However, diffusion is a timedependent process that could be enhanced by increasing the time allowed between pesticide application and percolation. In our study, the diffusion period was restricted to 6 days, which may limit diffusion effects. Moreover, during this short period significant degradation, that would confuse result interpretation, might not take place. Indeed, for two soils of the panel (Bouzule clay and loam soils) bentazon mineralisation after
7 days of incubation at $20 \pm 2{ }^{\circ} \mathrm{C}$ raised the initial amount by 0.3 and $0.2 \%$, respectively (Boivin, 2003).

Finally, diffusion and leaching may be significantly affected by soil adsorption (Letey and Farmer, 1974). Within the framework of our experiment, however, bentazon distribution coefficients $(\mathrm{Kd})$ revealed weak interactions with the soils studied (from 1.2 to $1.9 \mathrm{~cm}^{3} \cdot \mathrm{g}^{-1}$ ), despite their contrasting physicochemical properties (Tabs. I, II). In the case of slightly soluble and/or highly retained molecules, the adsorption process may be reconsidered.

Neither bentazon leaching nor its redistribution in fine porosity compartments were affected by the application of the product in a greater volume of water solution on wet soil aggregates. It would appear that saturating soil at $100 \%$ of its water capacity was sufficient to allow diffusion and that a 6-day period allowed the experimental system to reach a relative equilibrium state between liquid and solid phases.

Bentazon application on dry aggregates in a 50 times greater volume of aqueous solution led to a herbicide redistribution profile close to the one obtained after an application on wet soil. Proportionally, pesticide amounts leached by percolation appeared to be roughly identical whatever the initial soil water content. The volume of highly concentrated bentazon aqueous solution used for treatment directly dampened the column's surface aggregates (without previous solubilisation). As a result, a part of the product is carried away through the aggregates by the creation of locally immobile regions that will not participate in diffusive exchanges with mobile water. Transfer in mobile water may be thus considerably reduced. In a laboratory study, Shipitalo et al. (1990) also showed weaker atrazine leaching in the case of soil blocks receiving low rainfall prior to a significant leaching rainfall, than in the case of dry soil.

\section{CONCLUSION}

Initial soil moisture at the time of pesticide treatment influenced bentazon mass transfer behaviour when application was carried out according to field conditions. After 6 days of equilibration, according to the soil studied, previous soil dampening had the effect of reducing the amounts leached from 35 to $77 \%$, compared with a treatment performed with a low volume on dry soil. In our experimental conditions, on wet soils, the decrease in bentazon availability to mass transfer was attributed mainly to product redistribution by diffusion towards immobile water spaces, where it is likely to be physically trapped. In such application conditions, pesticide leaching might also be reduced by its adsorption onto and into soil aggregates. On a field scale, such phenomena might be expected: the probability of a soluble pesticide being quickly transported by mass flow towards soil depth might be potentially lower when soil is wet at the time of treatment or when a low rainfall carries it away or favours its diffusion within aggregates. Moreover, this study allowed us to highlight the fact that pesticide application technique (volume) in a laboratory experiment was meaningful where transfer results are concerned. Adding a larger $1 \mathrm{~mL}$ volume had the effect of dividing bentazon within soil fine porosity, thereby reducing its availability to transfer and suppressing any difference in behaviour between dry and wet soil application conditions. 
Acknowledgments: This work was financially supported by INRA and Arvalis.

\section{REFERENCES}

Abernathy J.R., Wax L.M. (1973) Bentazon mobility and adsorption in twelve Illinois soils, Weed Sci. 32, 224-227.

Beulke S., Brown C.D., Fryer C.J., Van Beinum W. (2004) Influence of kinetic sorption and diffusion on pesticide movement through aggregated soils, Chemosphere 57, 481-490.

Boivin A. (2003) Disponibilité Spatio-Temporelle et Transfert des Pesticides dans le Sol, PhD thesis, pp. 96-134.

Boivin A., Cherrier R., Perrin-Ganier C., Schiavon M. (2004) Time effect on bentazone sorption and degradation in soil, Pest Manage. Sci. $60,809-814$.

Brown C.D., Hodgkinson R.A., Rose D.A., Syers J.K., Wilcockson S.J. (1995a) Movement of Pesticides to Surface Waters from a Heavy Clay Soil, Pestic. Sci. 43, 131-140.

Brown C.D., Rose D.A., Syers J.K. (1995b) Effects of preferential flow upon the movement of pesticides and a conservative tracer from a heavy clay soil, in: Proceedings of BCPC, Warwick, UK, pp. 93-98.

Duchauffour P. (1970) Précis de pédologie, $3^{\mathrm{e}}$ ed., Masson, Paris.

Geissbuhler H., Haselbach C., Aebi H. (1963) The fate of N'-(4-chlorophenoxy)-phenyl-NN-dimethylurea (C-1983) in soils and plants: I. Adsorption and leaching in different soils, Weed Res. 3, 140-153.

Green R.E., Yamane V.K., Obien S.R. (1968) Transport of atrazine in a latosolic soil in relation to adsorption degradation and soil water variables, 9th International Congress of Soil Science 1, pp. 195204.

Grey T.L., Wehtje G.R., Walker R.H., Hajek B.H. (1996) Sorption and mobility of bentazon in Coastal Plain Soils, Weed Sci. 44, 166-170.

Gwo J.P., Jardine P.M., Wilson G.V., Yeh G.T. (1995) A multiple-poreregion concept to modelling mass transfer in subsurface media, $\mathrm{J}$. Hydrol. 164, 217-237.
Hagerman J.R., Pickering N.B., Ritter W.F., Steenhuis T.S. (1989) In situ measurement of preferential flow, ASCE National Water Conference and Symposium, University of Delaware, Newark 1-10.

Hartley G.S. (1964) The Physiology and Biochemistry of herbicides, Audus.

Huber R., Otto S. (1994) Environmental Behavior of Bentazon Herbicide, Rev. Environ. Contam. Toxic. 137, 111-134.

Jury W.A., Flühler H. (1992) Transport of chemicals through soil: mechanisms, models, and field applications, Adv. Agron. 47, 141-201.

Koch S., Flühler H. (1993) Non-reactive solute transport with micropore diffusion in aggregated porous media determined by a flow-interruption method, J. Contam. Hydrol. 14, 39-54.

Letey J., Farmer W.J. (1974) Movement of pesticides in soil, in: Guenzi W.D. (Ed.), Pesticides in soil and water, Soil Science Society of America, Madison, pp. 67-94.

Nye P.H. (1979) Diffusion of ions and uncharged solutes in soils and soil clays Adv. Agron. 31, 225-272.

Rao P.S.C., Green R.E., Balasubramanian V., Kanehiro Y. (1974) Field Study of Solute Movement in a Highly Aggregated Oxisol with Intermittent Flooding: II. Picloram, J. Environ. Qual. 3, 197-202.

Shipitalo M.J., Edwards W.M., Dick W.A., Owens L.B. (1990) Initial Storm Effects on Macropore Transport of Surface-Applied Chemicals in No-Till Soil, Soil Sci. Soc. Am. J. 54, 1530-1536.

Van Genuchten M.T., Wierenga P.J. (1976) Mass transfer studies in sorbing porous media. I. Analytical solutions, Soil Sci. Soc. Am. J. 40, 473-480.

White R.E., Dyson J.S., Gerstl Z., Yaron B. (1986) Leaching of Herbicides Through Undisturbed Cores of a Structured Clay Soil, Soil Sci. Soc. Am. J. 50, 277-283.

Yaron B., Calvet R., Prost R. (1996) Soil Pollution Processes and Dynamics, Springer, Berlin.

Youngs E.G., Leeds-Harrisson P.B., Garnett R.S. (1994) Water uptake by aggregates, Eur. J. Soil Sci. 45, 127-134. 